\title{
DESCRIPTION OF A \\ MACHINE FOR DRILLING INSTEAD OF PUNCHING WROUGHT IRON PLATES.
}

BY MR. JOHN COCHRANE, OF DUDLEY.

The Drilling Machine described in the present paper was designed for the purpose of drilling a large number of holes in wrought iron plates, in a case where it was considered impracticable to punch the holes with sufficient accuracy. The plates are required for the construction of the two main side girders of the new railway bridge over the Thames at Hungerford, the spans of which are 154 feet clear; and as, the bridge has to carry four lines of railway without any intermediate girders, the two side girders are required to be of very great strength, and are therefore being constructed of as many as five plates, each $\frac{5}{8}$ inch thick, besides four rows of 6 inch angle irons, rivetted through with inch rivets so as to form one plate of great strength and soundness. Hence the necessity that the holes in the several plates should correspond with perfect accuracy; and also that they should be truly parallel or cylindrical through each plate, so as to ensure their being completely filled by the rivets when rivetted up, which with more than three thicknesses is impracticable when the holes are punched, as they are then always larger on one side of the plate than the other.

The machine is shown in Plates 39 to 42 : Figs. 1 and 2, Plate 39, are a front elevation and plan; and Figs. 3 and 4 , Plates 40 and 41 , are longitudinal and transverse sections to a larger scale. The plate to be drilled is placed on the table $A$, and surrounded by a wrought iron frame securely bolted on the table, within which the plate is made fast in the proper position by set screws at each corner, being supported underneath upon four longitudinal bearers and held down above by three transverse bars. The table $A$ is guided by the two end frames $B$, and is raised by water pressure by means of the two 
cylinders $\mathrm{C}$ fitted with rams $\mathrm{D}$. The water pressure employed for raising the table up to the drills when a fresh plate has been fixed is given by a tank placed at a suitable height above the machine, from which the water is admitted by a two-way cock through the pipe $\mathrm{E}$ to the cylinders $\mathrm{C}$. This pressure is not sufficient to make the drills act, but the necessary pressure against the drills is obtained by an accumulator, consisting of an upright cylinder, fitted with a plunger weighted to the required amount. The two-way cock from the tank is closed and the valve from the accumulator opened, and the drilling then proceeds; as soon as it is completed, the valve is closed, and the cock opened to the waste pipe, so that both pressures being removed the table falls by its own weight the desired distance, and the drilled plate is removed to make room for another. By this arrangement the heavy pressure of the water in the accumulator is not wasted in raising the table up to the drills, but is reserved for giving the required working pressure in drilling. The weight of the table is partly counterbalanced by the balance weights $F$, in order that it may be raised with sufficient rapidity up to the drills when the plate has been fixed ready for drilling; but sufficient preponderance is left to enable it to fall away quickly enough from the drills when the water pressure is removed.

The drills $G$ are carried in two girders at the top of the machine, and driven from the two horizontal shafts $\mathrm{H}$ through the intervention of the bevil wheels and vertical shafts $I$, as shown in Figs. 3 and 4, Plates 40 and 41. In designing this machine cost had of course to be considered, and it was necessary to compensate by a saving in time for the greater expense of working occasioned by drilling instead of punching the plates. The machine is therefore arranged so as to drill all the holes in one plate simultaneously : there are eighty holes in each plate, 1 inch in diameter, arranged in four rows of twenty holes each; each of the two horizontal driving shafts $H$ drives ten vertical shafts $I$, and each vertical shaft drives four drill spindles $G$, the pinions of which are fixed at different levels around the centre vertical shaft I so as to run clear of one another. The bushes at the lower end of the drill spindles are made of wrought iron, bevilled and faced with steel at the bottom to receive the upward pressure put 
upon the drills in working, as shown enlarged in Fig. 5, Plate 42. These bushes are bored out to $\frac{1}{8}$ inch larger diameter than the drill spindles, with the exception of about $\frac{1}{2}$ inch length at the bottom, which is sufficient length of guide to ensure the drills running steadily; for when the machine was first got to work it was found that the drill spindles became chafed in running, by contact with the entire length of the bushes, and the latter were therefore bored out as described, without any diminution of steadiness in working; the space thus left in the upper part of the bush forms an oil chamber by which the shoulder of the drill spindle is kept constantly lubricated. The drills have tapered sbanks fitting into the sockets of the spindles and secured by set screws, as shown in Fig. 5 , so as to admit of any drill being speedily replaced in case of injury, or removed for sharpening. The simultaneous lubrication of all the drills while in work is effected by the plate being immersed in soap suds, which are con within the frame that surrounds the plate and drawn off through pipes at the sides when required.

In ordinary drilling machines the time when the drills are most frequently broken is just when they are coming through the plate, when there is not enough thickness of metal left to stand the working pressure on the drills; and in order to provide against injury to the drills at that time in the present machine, there are four spiral buffer springs $\mathrm{K}$, shown enlarged in Fig. 5, Plate 42, fixed in the upper frame and pressing on the corners of the table $A$, which oppose an increasing resistance to the upward pressure of the rams $D$; so that the pressure on the drills is gradually diminished as they work through the plate, and the table comes in contact with a fixed stop as soon as the drills are completely through, which prevents them from entering the table itself. The springs admit of adjustment in height according to the length of the drills, so as to allow for variation arising from wear of the drills by work.

The use of water pressure was adopted for raising the table of the machine, because it is important to raise and lower it with rapidity until the plate comes against the drills, when the pressure is required to be greatly increased to make the drills act. Had the lifting of the 
table been performed by gearing, much time would have been lost: for the feed would necessarily have been slow, and it would have taken much longer to raise and lower the table than to drill the holes; and to arrange a variety of speeds would have rendered the machine so complicated as to be almost useless. With the water pressure the feed is under perfect control, and is regulated to be slow or fast exactly as required. The use of water pressure also affords the means of accurately measuring the amount of pressure necessary to be put upon the drills to make them work, and it has been found by experiment that the most economical load on one drill is 5 cwts., making a total upward pressure of 20 tons on the table of the machine, which is obtained by loading the ram of the accumulator with cast iron weights to the required extent. The drills are driven at a speed of 40 to 50 revolutions per minute, and at this speed the entire 80 holes of 1 inch diameter are drilled through a $\frac{5}{8}$ inch plate within 15 minutes, in the most perfect manner and without difficulty. The drills stand very well, being found to last on the average 10 bours without grinding. There is no necessity for previously marking the holes, but the plates are simply put on the table of the machine and adjusted by the set screws. The truth of the work is so complete that a number of the plates are put together indiscriminately, and four turned pins passed through the corner holes, when the lot are put on a planing machine and the sides and ends planed to gauges. The power required to drive one machine with 80 drills is about 10 horse power, the machine being driven by bands and pulleys on opposite ends of the two horizontal driving shafts $\mathbf{H}$, Fig. 1. The accumulator is kept charged by a pair of 1 inch pumps worked from the ordinary shafting by eccentrics.

The present machine is constracted to drill the holes in each row at 4 inches apart, centre to centre, and the plates thus drilled are for the top flange of the bridge girders; but to give the camber required in the girders, the holes in the plates for the bottom flange have to be at 3.995 inches apart, so that a second machine is required for these plates. In the ordinary mode of punching by template however, so small a difference in the distance of the holes could not be practically carried out. The arrangement of the plates in the top flange of the 
girders is shown in Figs. 6 and 7, Plate 42 ; Fig. 6 is an edge view of the flange, showing the successive layers of plates breaking joint transversely, (the thickness of the plates being exaggerated four times); and Fig. 7 is a plan showing the arrangement of the plates in each of the five layers breaking joint longitudinally.

This machine has now been at work for about two months, and has so thoroughly answered the purpose intended that two others are being completed as rapidly as possible.

Mr. J. Cochrane showed a specimen of a plate with the holes drilled by the machine, and one of the drills used. He explained that in the girders for which the plates were required all the plates were arranged to break joint transversely of the girder, so that there were no additional covering plates at the joints, but four thicknesses of plate gave the calculated strength of the girder, and the fifth plate was then added to take the place of covering plates. As the flange was too wide to be made in a single plate, it was formed of two plates laid side by side, a wide plate with 4 rows of holes and a narrow one with 2 rows, which were alternately reversed so as to break joint longitudinally as well as transversely. This constrüction required the plates to be very accurate in dimensions so as to fit exactly together, which would have caused considerable trouble and expense in the ordinary mode of work with punched holes : but with the present machine the holes were drilled with such absolute accuracy and uniformity of pitch in every plate, that the plates were simply put upon the drilling machine without any special adjustment, and for planing the edges afterwards they were adjusted on the planing machine by four turned pins put through the corner holes; the edges were planed down to a gauge from the side of these turned pins, so that the distance from the pins to the edges was just half that between two adjoining holes; consequently when the plates were put together in the girder the two half spaces made up exactly the uniform pitch of the rivet holes in the five thicknesses of plates, throughout the whole 
length and width of the girder. A length of about 70 feet of the girder flange was now laid together at the works, which the members would have an opportunity of seeing the next day, as well as the drilling machine in operation; the holes in the plates fitted so accurately throughout that a 1 inch pin could be driven through the set of five thicknesses at any hole with a light hand hammer.

Mr. T. Down asked whether there was not a difficulty in getting the drills to stand equally over the whole surface of the plate; he would have feared there would be frequent delays from some of the 80 drills getting dulled and not cutting properly.

Mr. J. Cochrane replied that there was very little difficulty in practice from the drills failing, for the men soon found out those that stood the work well, and set aside the softer ones to be tempered again to a harder edge. The good drills stood for a whole day's work of 10 hours without grinding; and the pressure was so uniform and steady that the drills cut very regularly and smoothly, turning out long spiral shavings like the specimens shown. The principal difficulty experienced was from variation in the hardness of the plates, and occasionally a harder plate would dull some of the drills, which had then to be replaced; but a stock of 20 or 30 spare drills was kept ready for use, and any drill was easily changed in a few moments by simply slacking the set screw and tapping the drill, when it dropped out of the socket which was slightly tapered; the table of the machine was lowered for removing the drill, and raised again as soon as the new one was fixed.

Mr. W. Richandson asked whether any superior quality of steel was used for the drills, to enable them to stand the work better; and whether Mushet's steel had been tried, as he had heard it was of better quality and gave a more durable cutting edge that stood the work longer than ordinary steel without grinding up again.

Mr. J. Cochrane said they had used only ordinary cast steel at present for the drills, but were now trying some experiments with other steel, and he expected might succeed in making them stand probably two days instead of one before grinding up again.

Mr. C. Markham referred to the Jacquard punching machine, which he had seen at work at the Canada Works, Birkenhead, 
punching the plates for the Victoria bridge at Montreal; it was constructed for punching a long row of holes simultaneously, giving the means of adjustment to any required variation of pitch, and the punching was done with remarkable truth and accuracy, and with a rapidity which rendered the machine admirably adapted for bridge work. The Jacquard machine was no doubt a very costly one; but in great works such as the Britannia and Victoria bridges the first cost was of comparatively little consequence. He feared the expense of drilling the holes would be found very great.

Mr. J. Cochrane believed the cost of the Jacquard machine was $\mathfrak{f} 3000$ or $\mathbf{f} 4000$, which would limit its application to a work of the most extensive kind, such as the bridges alluded to; but it was adapted only for punching, and punched holes were so inferior in accuracy to drilled holes as to be quite inadmissible in the present case.

Mr. J. Fensie considered they were greatly obliged for the description of the drilling machine: this was a new application of drilling to a class of work in which it would prove of great value, being so far superior in accuracy to punching. However carefully punching might be done, a punched hole was never so true as a drilled one; and besides the injury done to the iron in drifting the holes afterwards to make them fit, the pressure on the plate in punching put a strain upon it and made it slightly hollow all round the hole, which prevented the plates being closed up so tight in rivetting. He thought drilling would be particularly advisable for the sides of fireboxes in locomotive boilers, where accuracy in the rivet holes was of so much importance, on account of the plates being required to fit correctly in all directions. Some of the locomotive boiler ends on the Midland Railway had lately been made with the holes drilled instead of punched, and it was found that the expense of drilling was bat little more than that of punching, while the drilled plates went together beantifully, saving all trouble of rimering or drifting to make them fit.

Mr. J. Cochrane observed that it was well known to be impossible to punch a cylindrical hole, on account of the bolster being necessarily somewhat larger than the punch, so that the hole must be taper, as the bottom end of the burr punched out filled the bolster; in punching 1 inch holes through a $\frac{5}{8}$ inch plate, the diameter of the holes would be 
about $\frac{1}{16}$ inch greater on the underside of the plate than on the upper side. In rivetting only two plates together the holes could be matched with the small ends next each other, as in ordinary boiler work; but with three or more plates it was practically impossible to make the rivet fill the hole by hand rivetting, on account of the cones, and the only way of doing it then was by a rivetting machine. He fully agreed in the importance of adopting drilling instead of punching for boiler plates, and thought their strength would be much increased thereby; in a great number of cases of boiler explosions the plates had given way through a rivet hole, apparently in consequence of the iron having been strained by forcing the punch through, and often further weakened by the rough drifting process.

Mr. E. A. Cowper observed that drilled holes were undoubtedly far more true than punched holes could possibly be, and were particularly suitable for the work described in the paper, on account of the great accuracy necessitated by the plates having all to break joint to such an extent. He enquired what was the cost of drilling by the machine as compared with punching the holes. There was of course a saving of expense in fitting the work together when the holes were drilled; for in punching, the iron became stretched at each hole, and a long angle iron might be stretched in this way as much as $\frac{1}{2}$ inch in 10 feet length; so that a different template had to be used for marking out the holes in the angle iron, in order to allow for the stretching. The Jacquard punching machine that had been referred to was not to be compared with the drilling machine in point of accuracy : but where punching was good enough, it was useful for punching a large number of holes at a time, and especially for punching plates to a particular pattern, as where a certain number of the holes had to be omitted in some of the rows.

Mr. H. C. Hurry asked how a uniform length of the drills was ensured, and whether their unequal wear did not cause some difficulty, as they would then not all bear on the plate at starting. He suggested whether the machine could be arranged for altering the pitch of the holes, that it might admit of more general application; for it would materially affect the expense of drilling if a special machine were required for every different pitch. 
Mr. J. Cocurane replied that no difficulty was occasioned by difference of length in the drills, since the feed by the water pressure was completely under control. On first getting the machine to work, the drills had been made of different lengths, because there was a deficiency of power for driving the machine; so that some of the drills were nearly through before others had begun cutting, thus saving power at the expense of time. The buffer springs acted so perfectly in easing the pressure when the drills were coming through, and the admission of water could be so exactly regulated, that it was possible to work with one drill only: the time of drilling was of course affected by having different lengths of drills, and the longest must not be so long as to go into the table of the machine.

As to the comparative cost of the work, with 80 holes in each plate drilling was no doubt much cheaper than punching; but with only half the number of holes the cost would probably be about the same as in punching. Drilling was however much safer and more accurate, and caused a great saving in putting the work together, an advantage of particular importance in the case of work manufactured for sending abroad for foreign railways: the increased cost in fitting up the machine at first would be fully repaid by the superior work produced, and would prove the cheaper plan in the end.

Mr. C. Markham asked how long it took to put the plate into the machine and remove it when drilled, besides the time of drilling.

Mr. J. Cochrane replied that 5 minutes were quite enough for fixing and changing the plate, making 20 minutes the total time for each plate; but often only 4 or 3 minutes were occupied, instead of 5 .

Mr. W. Richardson said that in the cotton spinning machinery manufactured at Messrs. Platt's works a large number of holes had to be drilled only $\frac{5}{8}$ inch asunder; and as the drill spindles conld not be geared nearer than every five holes, after one lot of eight holes had been drilled the drill carriage was moved forwards $\frac{5}{8}$ inch and eight more holes were drilled, and so on until the four intervening series of holes were all drilled, when the carriage was moved on and a fresh series of holes commenced. The holes had to be drilled conical, and to make them all the same size the bottoms of the drill spindles were furnished each with a screw, so as to vary the depth of the drill 
sockets; and the drill sockets were made parallel instead of taper, with two set screws on opposite sides in order to avoid the drill being thrown out of truth by the pressure of a single set screw on one side.

Mr. J. Cochrane said that in the machine described in the paper, with 4 inches pitch for the drills, the space for the driving pinions was so close that there was barely room for the brass collars on the top of the spindles; and the collars had to be reduced to less than $\frac{1}{8}$ inch thickness to give sufficient clearance for the pinions. They were so close run for room that in the second machine, for drilling the plates of the bottom flinge of the girder, where the pitch of the holes was only 3.995 inches, it was decided to drill only half the holes at a time, and then shift the plate for drilling the remaining holes. It would be very expensive to introduce an arrangement for altering the pitch of the drills, for this would add greatly to the complication of the machine; it was cheaper to cast a fresh top frame for a different pitch, and fit it complete with bushes for the drill spindles, but the same spindles and pinions could be used when there was only a little difference in the pitch, as in the present case.

Mr. C. Littue enquired whether any experiments had been made on the comparative strength of drilled and punched plates.

Mr. J. Cochrane had not tried the comparative strength, but understood that in some experiments made by Messrs. Sharp the strength of boiler plates was found to be materially increased by having the holes drilled instead of punched.

The Chalrman had no doubt punched holes could not be so good as drilled ones, and the men were seldom careful enough in setting out the holes and holding the plate correctly under the punch. But by drilling much greater accuracy was obtained, and he thought the plan of drilling would be highly advantageous for boiler making and ship building, in both of which there was at present room for great improvement.

He proposed a vote of thanks to Mr. Cochrane for his paper, which was passed.

The following paper, communicated through $\mathrm{Mr}$. Alexander $\mathrm{B}$. Cochrane of Dudley, was then read :- 
Fig.1. Front Elevation.

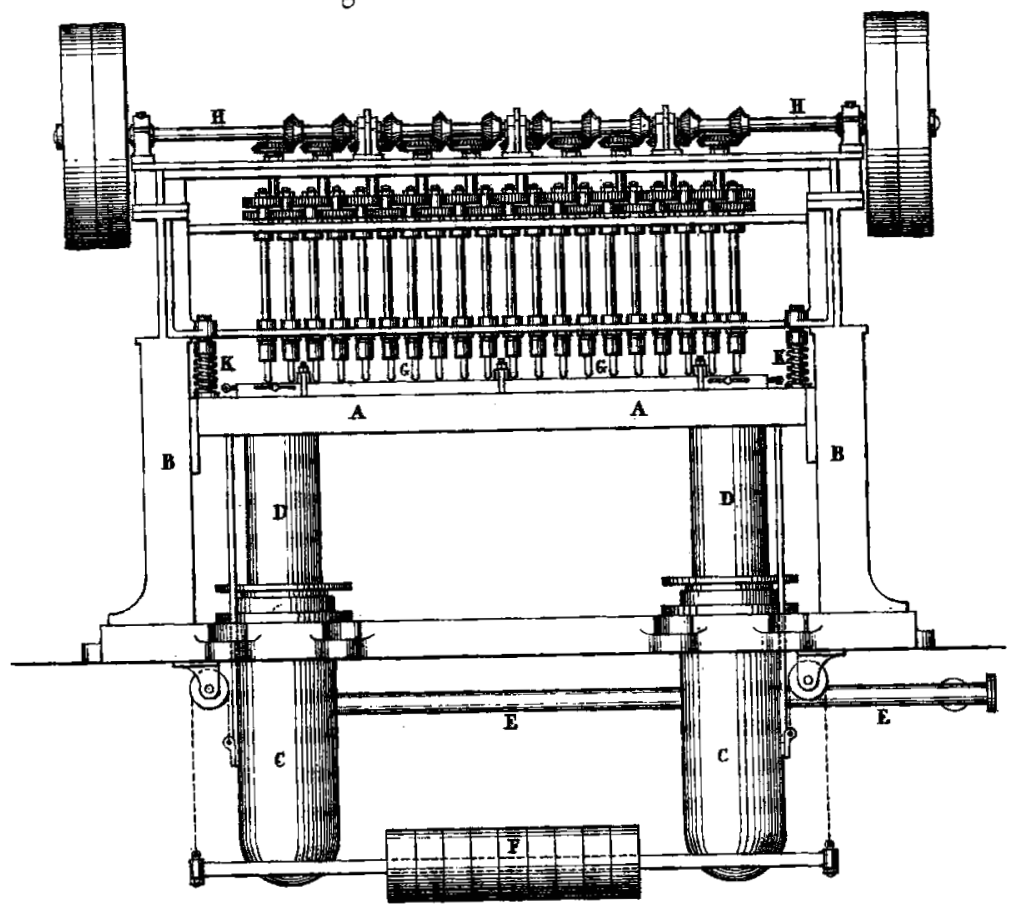

Fig. 2. Plan partly sectional.

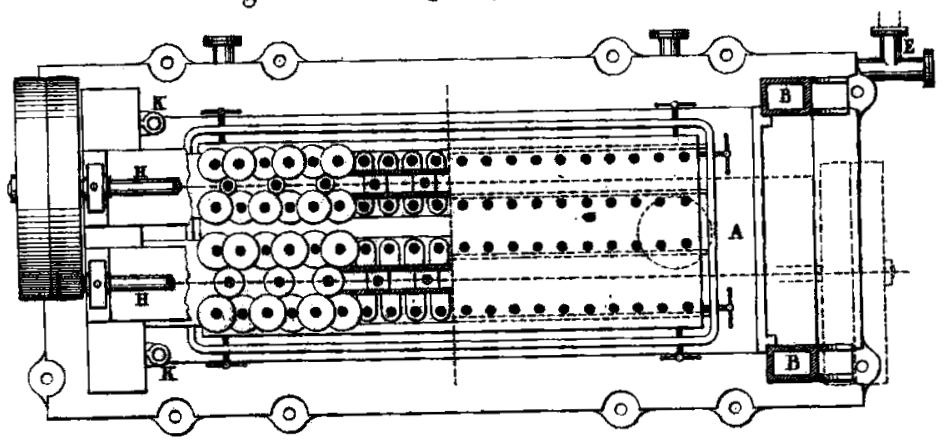

Srale $1 / 40^{\text {th. }}$

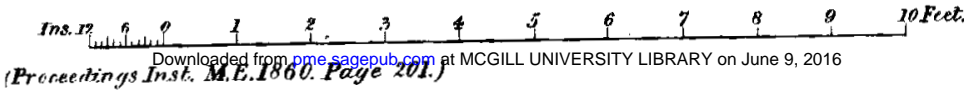


DRILLING MACHINE.

Fig. 3. Iongituidinal Section, entarged.

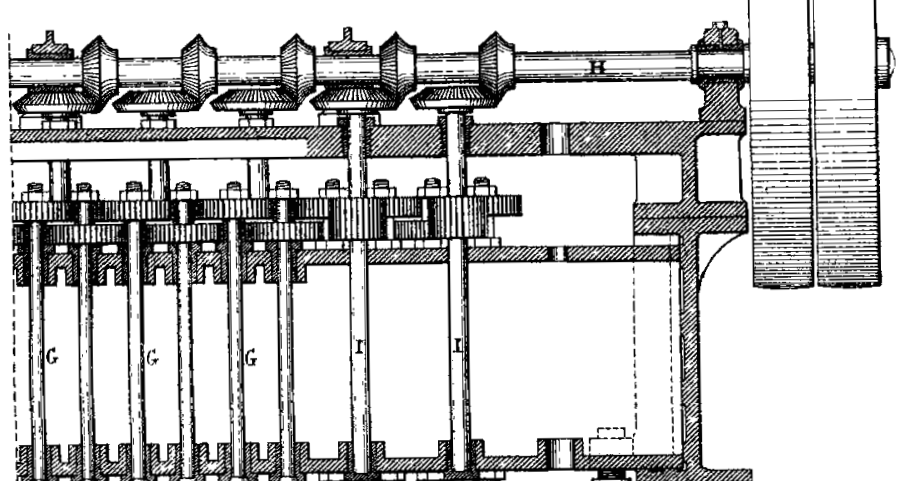

Plake 40.
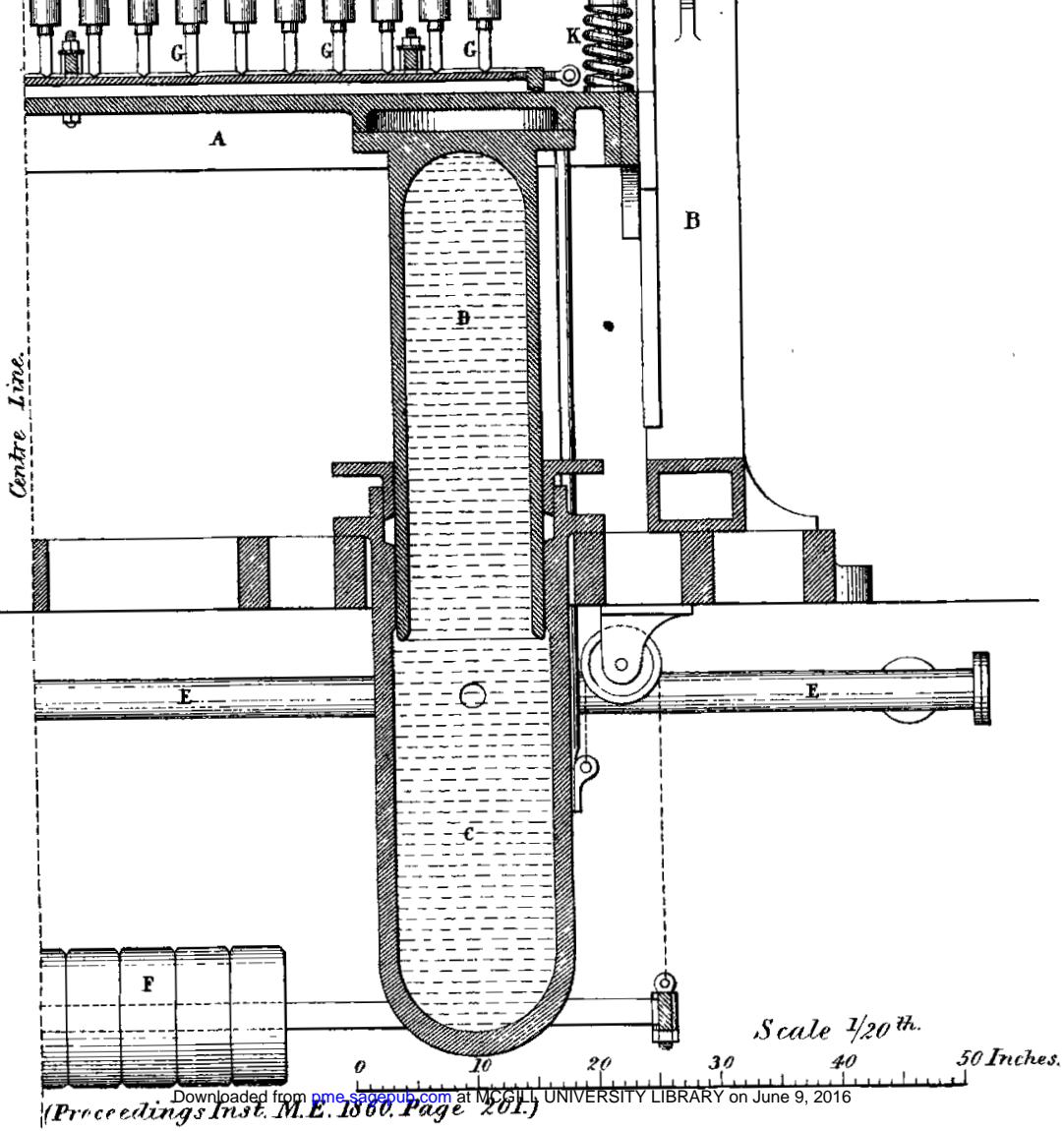


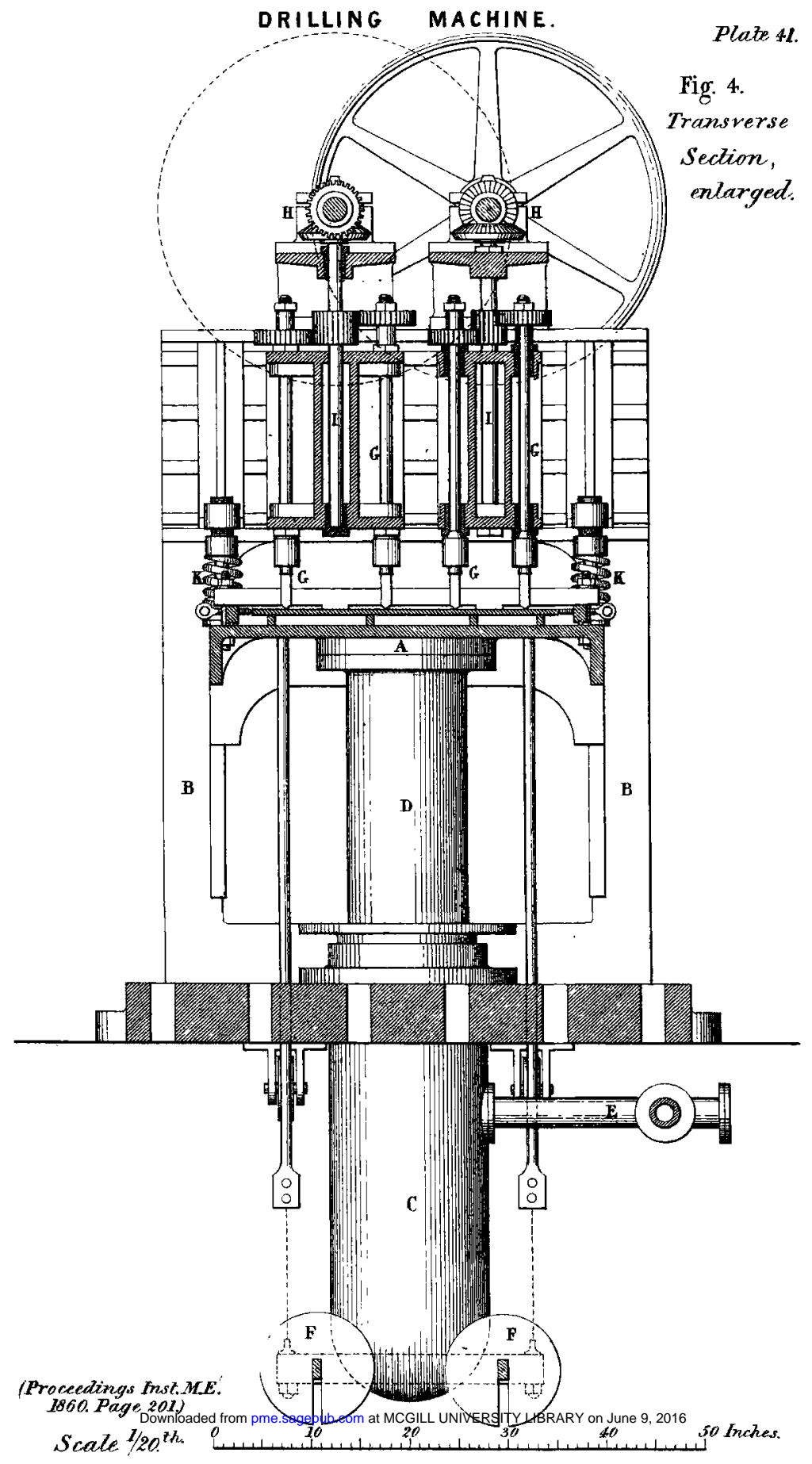




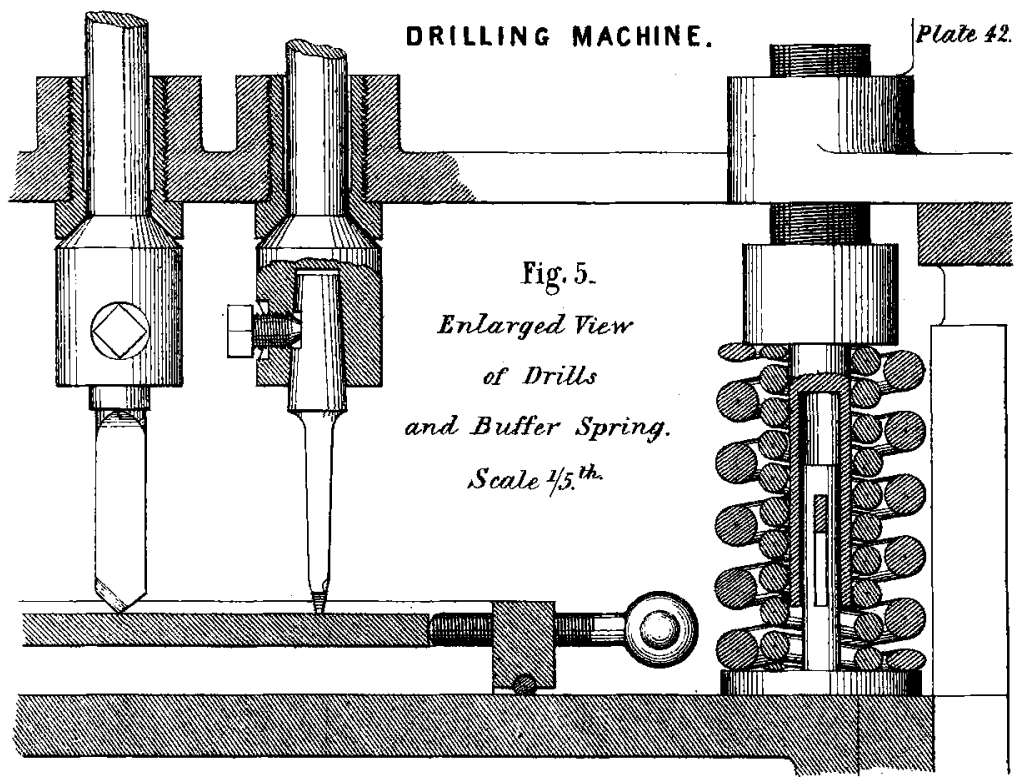

Arrangement of Plates in Top Flange of Girder. Fig.6. Elge View. (Thichness of Plates exaggerated four times.)

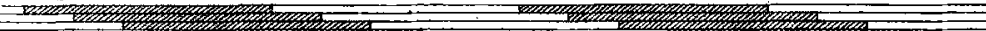

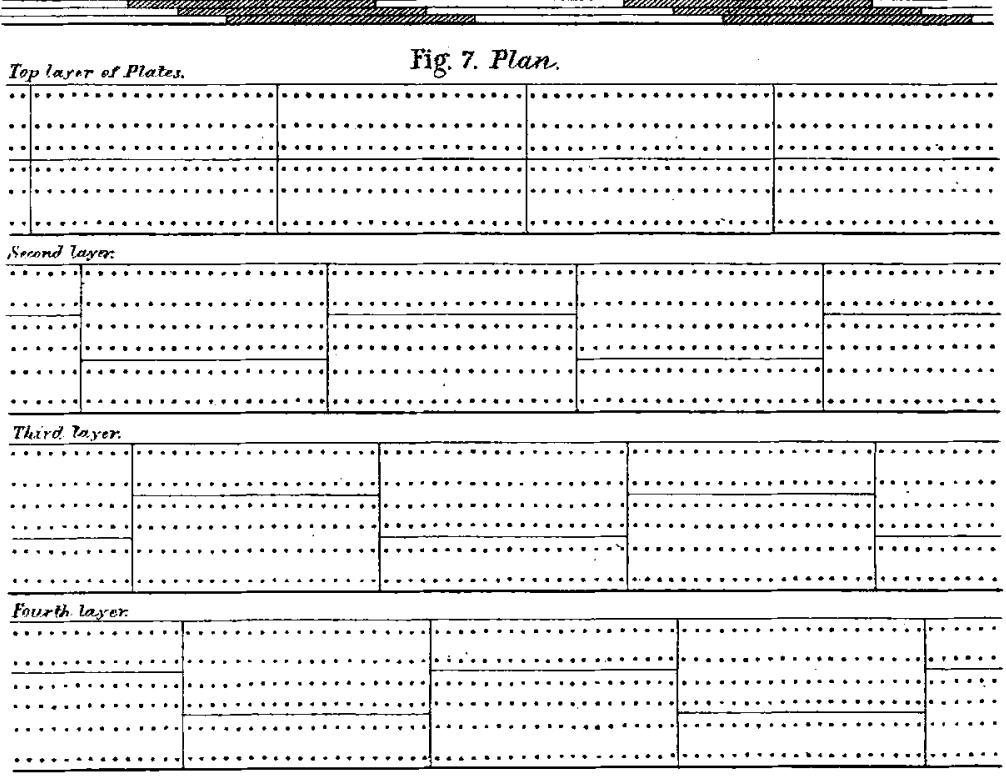

\section{Fich tayer:}

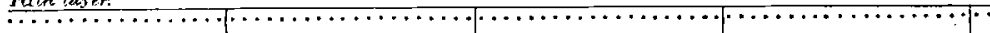

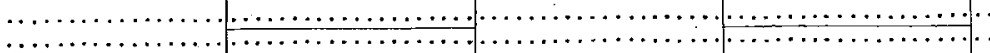

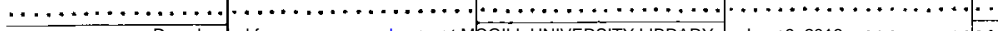
$\ldots \ldots \ldots \ldots$. . . . . .

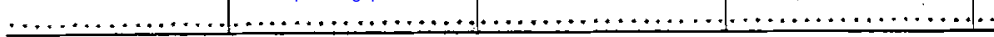

